\title{
Los periódicos en las redes sociales: audiencias, contenido, interactividad y estrategias comerciales
}

\author{
Miguel TúÑEz LÓPEZ \\ Universidad de Santiago de Compostela \\ miguel.tunez@usc.es
}

Recibido: $16 / 03 / 2011$

Aceptado: 26/07/2011

\begin{abstract}
Resumen
Las redes sociales se han consolidado, con millones de usuarios, como un soporte de comunicación y un canal de flujos informativos en los que las relaciones interpersonales conviven con estrategias organizacionales de todo tipo. Este artículo analiza la actividad y los contenidos de los 23 diarios (generalistas, económicos, deportivos y gratuitos) de mayor tirada en las tres redes sociales 'puras' con más seguidores en España (Facebook, Twitter y Tuenti), atendiendo principalmente a cuatro parámetros: interactividad; elaboración y presentación de contenidos; audiencias y seguidores; y estrategias comerciales.
\end{abstract}

Palabras clave: redes sociales, interactividad, Facebook, Twitter, Tuenti

\section{The Newspapers in the Social Networks: Hearings, Content, Interactivity and Commercial Strategies}

\begin{abstract}
The social networks have been consolidated, with million users, as a support of communication and a channel of informative flows in which the interpersonal relations coexist with strategies organizational of all kinds. This article analyzes the activity and the contents of 23 diaries (general, economic, sports and free) of major issue in three social networks with more followers in Spain (Facebook, Twitter and Tuenti), attending principally to four parameters: interactivity; making and presentation of contents; hearings and followers; and commercial strategies.
\end{abstract}

Keywords: Social Networks, Interactivity, Facebook, Twitter, Tuenti

\section{Referencia normalizada}

TÚÑEZ LÓPEZ, Miguel (2012): "Los periódicos en las redes sociales: audiencias, contenido, interactividad y estrategias comerciales”. Estudios sobre el mensaje periodístico. Vol. 18, núm. 1, págs.: 221-239. Madrid, Servicio de Publicaciones de la Universidad Complutense.

Sumario: 1.Introducción. 2. Los medios en las redes sociales. 3. Hipótesis y método. 4. Resultados y discusión. 4.1. Audiencias de las redes sociales. 4.2. Los seguidores de los medios en las redes sociales. 4.3. Los contenidos. 4.4. ¿Bidireccionales o interactivos? 4.5. Estrategias comerciales. 5. Conclusiones. 6. Referencias Bibliográficas.

\section{Introducción}

Las redes sociales se han consolidado en un corto periodo de tiempo como un nuevo escenario de comunicación y se han convertido en un símbolo de la comunicación 2.0 en internet. Lo que comenzó siendo un punto de reunión entre conocidos también es ahora un escenario de negocio que empieza a ser estudiado e incorporado por los responsables de marketing de las principales compañías como un nuevo soporte a tener en cuenta en el diseño de sus estrategias de comunicación.

El intercambio de experiencias personales marcó el inicio de un nuevo escenario de relaciones sociales que ha ido creciendo progresivamente hasta ofrecer un volumen 
de usuarios que se cuenta por millones. Para todo tipo de organizaciones esa nueva posibilidad de contacto múltiple se hizo más atractiva porque la difusión es gratuita. La comunicación virtual fue tejiendo un enjambre de redes personales interconectadas en el que se mezclan entre sí los usuarios y las mismas redes a las que pertenecen. Y, a la vez, fue permitiendo la convivencia de los individuos y las organizaciones (o sus marcas) como usuarios activos que generan, difunden y consumen información.

Este nuevo escenario de comunicación y distribución de contenidos coincide con un momento delicado para los medios tradicionales impresos. Las inversiones publicitarias se recortan por la crisis y se diversifican por la multiplicación de medios y soportes. Las versiones electrónicas ofrecen productos similares a las impresas en una sociedad en la que cada vez hay más usuarios de internet.

Los entornos virtuales modifican también los hábitos de consumo de las audiencias y sus formas de relacionarse con los medios. La edad media de los lectores aumenta y la población disminuye. Los jóvenes son internautas casi desde niños y crean nuevas formas de ver y de leer los medios, a la vez que se convierten en usuarios activos que dejan de ser solo receptores y pasan a ser también generadores de contenidos. Ellos han encontrado en internet un nuevo hábitat de comunicación. Un 94,1\% de la población entre 16 y 24 años es usuaria de internet, según el Instituto Nacional de Estadística. Entre 25 y 34 años la cifra ya desciende al $85,3 \%$ y los porcentajes siguen disminuyendo a medida que aumenta la edad.

Casi todos los jóvenes usan internet pero son los adultos los que, mayoritariamente, leen los periódicos. Algo similar ocurre con los diarios impresos. En los últimos diez años, el índice de penetración de la prensa diaria de pago ha descendido en la población de 14 a 24 años: 466.948 jóvenes menos en 2010 que en 2000. La cifra se matiza por la disminución de la población. Porcentualmente el descenso es de solo 2 puntos. En datos relativos, proyectando el porcentaje de 2000 sobre la población de 2010, equivale a unos 103.000 jóvenes menos.

Como alternativa, los medios tradicionales han reorientado sus estrategias de fidelización hacia las herramientas, las aplicaciones y los soportes más que hacia los contenidos. Se potencia la presencia en Twitter y en Facebook para difundir los temas del diario on line, se abren las noticias a comentarios de los lectores y se fijan buzones de recepción de textos elaborados por los ciudadanos pero no se reorientan los contenidos con nuevos productos especialmente dirigidos hacia los jóvenes.

Los medios innovan en distribución y en diseño para hacer más atractivo el producto y potencian aplicaciones on line conscientes de que la red se consolida como el nuevo escenario de comunicación interpersonal, social y mediática. Los índices de uso de internet superan el $90 \%$ en las franjas de población adolescente y joven a la vez que la telefonía móvil se perfila como un soporte atractivo (el nuevo escenario de negocio), que lucha por hacer compatible un aumento de la superficie de las pantallas con mantener el tamaño reducido del teléfono.

Todo está en la red, pero la red ha ido creando formas propias de intercomunicarse y de relacionarse. La universalización de la posibilidad de ser emisor de mensajes que lleguen a grupos numerosos a través de internet ha provocado la ruptura del esquema tradicional de comunicación lineal y su sustitución por modelos circulares o en ra- 
cimo en los que cualquier individuo puede ser receptor, y emisor (o reemisor) a la vez y está conduciendo a los medios a cambiar su actitud con la audiencia del discurso al diálogo (TúÑEZ, SOlANA y ABEJón: 2010).

Las redes sociales marcan un nuevo entorno y un nuevo soporte comunicativo con los ciudadanos y las organizaciones en un modelo de comunicación multidireccional (todos con todos), pero con el compromiso de interactuar, es decir, de ser un usuario proactivo en las comunidades virtuales en las que uno decida libremente estar. La red es global pero se teje con pequeñas redes en las que cada miembro decide a quien acepta en su grupo de interlocutores para interactuar con ellos.

Mantener el contacto con los miembros de la red y relacionarse con grupos de intereses comunes son actividades frecuentes en redes sociales. Pero también lo es cada vez más (con una incidencia que en España aún está por debajo de la media) usarlas para conectar, gestionar u organizar grupos de clientes y para potenciar el posicionamiento de una marca. La lógica de funcionamiento es bien sencilla: un flujo de millones de usuarios que intercambian mensajes. La técnica debe orientarse, al menos, en un doble sentido: a) como un usuario más interrelacionándose con los otros usuarios y b) promoviendo o (aportando) mensajes para que circulen de grupo en grupo en las redes como parte de la comunicación que los usuarios gestionan. Hablamos, de forma indirecta, de marketing de relaciones y de marketing viral.

Los mercados han adquirido una dimensión global en el espacio y atemporal en el tiempo, gracias al desarrollo de internet en todo el planeta. Las organizaciones han de tener claro que no solo se han modificado las relaciones entre los participantes en el proceso de intercambio, sino que también los productos incorporan y admiten cada vez más información, recursos, potencialidades y particularidades.

El marketing de relaciones (o interactivo) supone un regreso al pasado, pero usando las tecnologías actuales. Se trata de un enfoque "retro" de las relaciones de intercambio con el mercado, intentando emular la figura del viejo comerciante que conocía personalmente a su clientela, y a la vez un enfoque realista por su vocación de mantener a los usuarios actuales en lugar de procurar otros nuevos (SANTESMASES, 2007). Las redes se tejen por relaciones entre usuarios por lo que contemplarlas como escenario de negocio implica aceptar que se han de cuidar y promover esas relaciones para que perdure esa relación.

El boca a boca es tan antiguo como la propia humanidad pero la dimensión y la velocidad que adquiere gracias a las nuevas tecnologías son quienes permiten la aplicación del llamado marketing viral (SiverA, 2008). RUSHKOFF adelantó en 1996 sus bases: si un mensaje con unas características concretas llega a un usuario interesado, este se infectará de ese mensaje y estará preparado para seguir infectando a otros usuarios sensibles que a su vez transmitirán el virus de modo exponencial. El marketing viral consiste, pues, en la difusión rápida y masiva de un mensaje a través de internet promovida por la organización y realizada por los propios usuarios. Es lo mismo que ocurre con los contenidos en las redes sociales.

En síntesis, el panorama podría resumirse apuntando que las audiencias de los medios tradicionales envejecen y las nuevas generaciones renuevan sus hábitos de consumo de medios y crean su propia programación con la descarga de vídeo y audio a 
la vez que se convierten en generadores de contenidos con los que inundan su nuevo hábitat: las redes sociales. La pregunta es si los medios impresos han sabido adaptarse a este nuevo entorno virtual interpersonal.

\section{Los medios en las redes sociales}

Los medios de comunicación necesitan promover sus estrategias relacionales para estar en las redes sociales procurando que el flujo de seguidores no sea un trasvase de la web a la red social sino más bien al contrario o, en todo caso, una duplicidad de presencias. Y, al mismo tiempo, explorando la posibilidad de aprovechar la red personal de cada seguidor como un nuevo grupo de interés que intentar atraer como audiencia del medio.

Web y red social son complementarias. En la web el usuario es proactivo, entra y busca información. En la red, la proactividad se decanta un poco más hacia el mensaje: la noticia que el medio cuelga en su muro de Facebook espera a los seguidores de ese medio en el muro de entrada de cada uno de ellos y lo aborda cuando va a ver sus contactos personales. El envío a través de Twitter es una comunicación sintética, breve, a los seguidores. Es una de las premisas para un óptimo aprovechamiento de las redes en ámbitos comerciales: la organización ha sido aceptada pero su comportamiento se desarrolla en un campo que está mas en la esfera de lo privado que de lo público porque las redes son espacios de comunicación interpersonal que han desarrollado sus propios códigos y pautas de conducta.

Las pautas son sencillas pero no siempre se cumplen. Si se busca trasvase de usuarios se debe facilitar el flujo con la incorporación de contenidos al muro del usuario o el envío por Twitter pero también destacando en la web el botón para convertirse en seguidor y en la red la dirección de enlace con el diario. Parece evidente que la información corporativa de presentación en el perfil es importante pero es fácil verificar en las redes que muchas cabeceras limitan esa información a enlaces a otras páginas del medio o del grupo al que pertenecen.

Hasta el dominio, el nombre, es determinante para que nos identifique sin equívocos y a la vez permita que nos localicen fácilmente ${ }^{1}$. Personalizar los contenidos, aportar enlaces o material que no solo sean noticias, activar recursos en las pestañas (eventos, notas, foros, galerías de imágenes), fomentar la participación de la audiencia y el reenvío de las informaciones a otros usuarios, promover el retorno hacia la web central, e iniciar la conversación (fomentar respuesta) y mantenerla (conversar, responder también) son normas de socialización de las organizaciones en la red que no siempre se cumplen en el caso de los periódicos.

${ }^{1}$ De los diarios analizados El Mundo Deportivo tarda en aparecer en los motores de búsqueda de Facebook; MARCA y marca son páginas diferentes. Y, en Twitter, tenemos con contenidos diferentes a $a b c$ es ("Twitter oficial del periódico $A B C$ con información, noticias actualizadas y medio de conversación con los lectores") y $A B C$.es ("Los temas de portada de $A B C . e s$, minuto a minuto") 
TABLA 1. Uso de Facebook en la comunicación de las organizaciones. Fuente: elaboración propia

\begin{tabular}{|c|c|}
\hline \multicolumn{2}{|r|}{ Decálogo para el buen uso de Facebook en la comunicación organizacional } \\
\hline $\begin{array}{l}\text { Respeto al } \\
\text { espacio personal }\end{array}$ & $\begin{array}{l}\text { La red es un espacio personal para cada uno de sus miembros. Y en las esferas } \\
\text { personales se utiliza un lenguaje coloquial, en primera persona (son amigos). Lo } \\
\text { cotidiano acerca. }\end{array}$ \\
\hline $\begin{array}{l}\text { Proximidad } \\
\text { afectiva }\end{array}$ & $\begin{array}{l}\text { Proximidad significa trato directo, de tú a tú, con textos que apelen y se interesen } \\
\text { por las experiencias personales. }\end{array}$ \\
\hline Mensajes breves & $\begin{array}{l}\text { Intervenciones cortas. No se trata de que se vea el mensaje sino de que se lea. Más } \\
\text { de cuatro líneas obliga al usuario a ejecutar la acción de "leer más", y no siempre se } \\
\text { hace. La entrada a Facebook es un muro, su comentario ha de ser como una pintada: } \\
\text { breve e intensa. }\end{array}$ \\
\hline Proactividad & $\begin{array}{l}\text { Los mensajes deben incluir una invitación a participar con comentarios (a veces una } \\
\text { pregunta simple es suficiente). En la red se habla y eso exige una actitud proactiva } \\
\text { que implica gestionar la comunicación para que sea realmente interactiva. Es } \\
\text { importante dar respuesta a los comentarios. Facebook no es un escenario para } \\
\text { pronunciar un discurso y que otros hablen sino para dialogar con los amigos. }\end{array}$ \\
\hline Frecuencia & $\begin{array}{l}\text { El muro está vivo. Sus intervenciones no perduran indefinidamente en el tiempo. La } \\
\text { interactividad necesita una dinámica de presencia frecuente en la red que nos } \\
\text { mantenga visibles pero sin saturar el espacio con aportaciones carentes de interés. }\end{array}$ \\
\hline $\begin{array}{l}\text { Visibles y } \\
\text { próximos }\end{array}$ & $\begin{array}{l}\text { Uso de recursos multimedia: pdf, videos, audio, fotos personales. La red aporta } \\
\text { visibilidad pero su actividad en la red puede aproximarle o distanciarle de su grupo } \\
\text { de amigos }\end{array}$ \\
\hline $\begin{array}{l}\text { Perfil } \\
\text { corporativo }\end{array}$ & $\begin{array}{l}\text { Apertura del perfil con información textual y visual de la organización. Además del } \\
\text { nombre, es el lugar para dar a conocer los objetivos, la función, la misión de la } \\
\text { organización. }\end{array}$ \\
\hline $\begin{array}{l}\text { Hablar y debatir } \\
\text { sin miedo a las } \\
\text { críticas }\end{array}$ & $\begin{array}{l}\text { Permitir y administrar la posibilidad de aportar contenidos y generar debate en los } \\
\text { foros. Mayoritariamente se lee lo que está en el muro, pero las herramientas de la } \\
\text { red están para ser usadas. Y Facebook también puede ser un escenario de debate } \\
\text { colectivo sin miedo a las críticas: el administrador tiene la última palabra y las } \\
\text { intervenciones en contra también pueden ser un útil avisador de riesgos. }\end{array}$ \\
\hline $\begin{array}{l}\text { Refuerce la } \\
\text { pertenencia al } \\
\text { grupo }\end{array}$ & $\begin{array}{l}\text { La organización debe estimular la pertenencia al grupo de seguidores. Facebook es } \\
\text { escenario de sorteos, de concursos, de promociones,... }\end{array}$ \\
\hline Red de redes & $\begin{array}{l}\text { Su presencia en Facebook por ser la más numerosa no excluye otras posibilidades. } \\
\text { Hacer red de redes con intercomunicación de las intervenciones ya posible. }\end{array}$ \\
\hline
\end{tabular}

\section{Hipótesis y método}

Un entorno para relacionarse, posicionarse como marca, visibilizar al medio y hacer que circule el producto informativo. Las redes sociales son a la vez soporte y canal de distribución; punto de encuentro y relación de los medios con su audiencia y de los individuos entre sí; escenario de negocio tanto como soporte publicitario como en estrategias de ventas de productos propios o de fidelización de usuarios al medio, tradicional $\mathrm{u}$ on line. ¿Aprovechan los medios todas estas posibilidades? ¿Están en las redes sociales con una actitud 2.0? ¿Elaboran contenidos para las redes o solo vuel- 
can los contenidos de sus versiones digitales como hacían en las primeras webs con los contenidos de los soportes tradicionales?

Esta investigación se acerca a las redes sociales y a los medios para estudiar los niveles de penetración y audiencia (seguidores, usuarios) de los principales diarios, analizar los contenidos que difunden y aproximarse a la estrategia que motiva el uso de espacios de comunicación interpersonal para la circulación de productos informativos. Es una investigación exploratoria que parte de la hipótesis de que los medios mantienen un comportamiento bidireccional pero no siempre interactivo en entornos 2.0 porque vuelcan sus contenidos pero no elaboran material especifico para las redes ni dialogan abiertamente con sus usuarios.

Metodológicamente se optó por un una revisión documental de estadísticas que permita analizar las frecuencias y motivos de uso de internet y las audiencias de las redes sociales (exclusivas y compartidas). También se realizó una medición propia a través del seguimiento de los principales diarios en las redes sociales con mayor número de seguidores. Se desestimaron las redes que funcionan a modo de portal, como Messenger, y se optó por las 'redes puras', las que básicamente se centren en el intercambio de información entre sus miembros. Los datos de la Asociación para la Investigación de los Medios de Comunicación (AIMC), Alexa.com y el Observatorio de Redes Sociales (Tercera oleada, febrero 2010) aconsejaron trabajar con Facebook, Tuenti y Twitter.

La muestra de análisis se determinó con los datos de Estudio General de Medios (complementados con las cifras de difusión de OJD) diferenciando diarios generalistas de pago (14: El País, El Mundo, El Periódico, La Vanguardia, Abc, La Voz de Galicia, El Correo, La Razón, La Nueva España, Heraldo de Aragón, Levante, Faro de Vigo, Diario Vasco y Público), de deportes (4: Marca, As, Sport y El Mundo Deportivo), de economía (2: La Gaceta y Expansión) y gratuitos (3: 20minutos, Qué y Adn). Las duplicidades de páginas en las redes sociales con el nombre de un mismo medio aconsejaron una verificación de los enlaces desde las páginas web de los diarios, que no en todos casos lo tienen activado 2 .

El seguimiento en estos veintitrés diarios en las tres redes sociales se hizo del 21 de febrero al 12 de marzo, y el estudio de contenidos del 21 al 27 de febrero, ambos incluidos. La ficha de seguimiento permitió registrar datos sobre número de seguidores, días y horas de actividad, número de comentarios de los usuarios, niveles de respuesta del medio, recursos utilizados, oferta de contenidos en la red, estrategias de fidelización y estrategias comerciales.

Para relativizar los datos de seguidores de cada medio en cada una de las tres redes se hizo una proyección estadística sobre las cifras de audiencia del EGM y sobre las

2 No se encontraron botones de acceso directo desde la web corporativa (diario on line) a $\mathrm{Fa}$ cebook desde Abc, La Razón y Heraldo de Aragón: A Twitter, desde La Vanguardia, Abc, La Razón, Heraldo de Aragón, Diario Vasco y Sport. Con Tuenti solo tienen enlace directo desde la web El País, La Voz de Galicia, La Nueva España, levante, Marca, As, Qué y, para compartir contenidos, 20minutos. 
cifras de tirada de OJD. Y, en los espacios de los medios en Facebook, una proyección del número de usuarios que aportan contenidos sobre las cifras globales de usuarios.

\section{Resultados y discusión}

El aumento progresivo del número de usuarios de las redes sociales permite hablar de una doble estructura de malla: i) las interrelaciones entre usuarios de la misma red social y entre los grupos de relaciones que forma (o al que pertenece) cada uno de ellos y ii) el aumento del número de redes a las que pertenece un mismo individuo que crea una segunda estructura en la que los cruces de relaciones se producen entre las diferentes redes.

Consideradas un fenómeno ya consolidado, las redes sociales han evolucionado como herramienta de comunicación interpersonal y de la esfera íntima a herramientas de comunicación personal y social en las esferas íntima y pública. También se han ido diferenciando de espacios similares que a modo de plataforma de comunicación o canal de mensajería ofrecen posibilidad de contacto interpersonal a través de la red.

TABLA 2. Uso de internet en los últimos 3 meses, por edades. Fuente. Instituto Nacional de Estadística

\begin{tabular}{|l|c|c|c|c|c|c|c|c|c|c|c|}
\hline Edad (años) & 10 & 11 & 12 & 13 & 14 & $16-24$ & $25-34$ & $35-44$ & $45-54$ & $55-64$ & $65-74$ \\
\hline Uso internet \% & 78,0 & 85,3 & 86,2 & 89,9 & 90,9 & 94,1 & 85,3 & 74,6 & 60,0 & 43,2 & 13,4 \\
\hline
\end{tabular}

La evolución de los últimos años coincide en mostrar el aumento del uso de internet desde la preadolescencia y en señalar las acciones de comunicación personal como las actividades más comunes. Nueve de cada diez jóvenes entre 16 y 24 años (90,5\%) declaran que acuden a internet para usar su correo electrónico, según la Encuesta sobre equipamiento y uso de tecnologías de la información y comunicación en los hogares 2010 del Instituto Nacional de Estadística (INE). El siguiente uso más frecuente de la red son los servicios de búsqueda de información sobre bienes y servicios $(82,9 \%)$. La encuesta no hace referencia específica a redes sociales pero sitúa en tercer lugar actividades similares de intercomunicación: chats, blogs, foros de discusión on line y mensajería instantánea $(78,8 \%)$.

Las descargas de ocio $(72,1 \%)$ (juegos, películas, imágenes o música) y subir archivos $(67,1 \%)$ son la cuarta y quinta actividad más frecuente. Buscar información sobre educación, formación u otro tipo de cursos es la sexta $(63,9 \%)$ y consultar internet para algún tipo de aprendizaje $(59,2)$, la séptima. Utilizar servicios relacionados con viajes y alojamiento $(55,8 \%)$, la octava. Los medios aparecen como novena actividad: un $54,4 \%$ de los que se conectan dicen que usan la red para leer o descargar noticias, periódicos o revistas de actualidad, y un 53,0\% para escuchar radios que emiten por internet y/o ver televisión on line.

La encuesta a internautas de 22 a 45 años que el Observatorio de las Redes Sociales (de la consultora The Cocktail Analysis) desarrolló en noviembre de 2010 concluye que el ordenador personal ha dejado de ser el único referente de acceso y el $36 \%$ de los usuarios de internet desde el teléfono móvil accede a redes sociales de forma diaria y el 50\% consulta el correo electrónico.

Las redes sociales son la puerta para colocar contenidos en los nuevos terminales de comunicación social, los móviles, toda vez que a través de ellas se puede mante- 
ner un servicio similar a las alertas de noticias de actualidad que algunos medios aún mantienen bajo fórmulas de pago por suscripción. Leer noticias no aparece específicamente en las utilidades del móvil en internet pero sí figura el acceso a las redes. Aumenta la oferta de aplicaciones y de servicios destinados a favorecer, respectivamente, el uso en movilidad con acceso gratuito a pequeñas redes (chat de blackberry, por ejemplo) y la geolocalización.

El incremento de propuestas de actividades en una misma red y de la multiplicación de puntos y formas de acceso está creando un sistema de híper comunicación que va modificando los hábitos iniciales de la redes (comunicación interpersonal) y que mueve los afectos como motor de pertenencia (encuentro con amigos) hacia el intelecto (redes temáticas o contacto con la actualidad informativa).

\subsection{Audiencias de las redes sociales}

De todas las redes sociales, Facebook es la que cuenta con más usuarios en todo el planeta, unos 600 millones. Estados Unidos es quien más usuarios aporta, unos 149 millones de miembros activos de los que el 70\% revisa su perfil diariamente. En España existen unos 13 millones de usuarios activos, de los cuales el 58\% entra a la red a diario $^{3}$.

Un $89.9 \%$ de los que respondieron a la $13^{\circ}$ encuesta (febrero 2011) de la Asociación para la Investigación de Medios de Comunicación (AIMC) señalan a Facebook como una de las redes que ha utilizado en el último mes: le siguen muy distanciadas Tuenti $(26,2 \%)$ y Twitter (21,9\%). En un tercer bloque aparecen LinkedIn $(14,3 \%)$ y Flickr (10,2\%), y a continuación todas las demás. El estudio refuerza la imagen de las redes como un espacio interpersonal (84,9\% la usan para relaciones de amistad), de uso frecuente (el $60.3 \%$ afirmó haber entrado el día anterior) y con margen de crecimiento (el 16\% no tiene perfil en ninguna red).

El registro de datos se ha hecho entre usuarios de la red por lo que resulta interesante atender a la manera habitual de contacto con el diario: un 54,8\% lee ediciones electrónicas e impresas, el 32\% solo las versiones on line y el 7,3\% solo las versiones en papel. El 93,1\% de los usuarios de internet dice que entre sus actividades en la red está la lectura de noticias de actualidad ${ }^{4}$. En el día anterior a responder a la encuesta, casi la mitad $(45,8 \%)$ había leído un diario impreso y el 77,8\% lo había leído a través de internet. En el recuerdo de las cinco últimas webs que habían visitado, los medios y las redes aparecen entre las más buscadas, siempre después de Google que encabeza la lista. Le siguen facebook.com (puesto 2), elpais.com (3), marca.com (4), elmundo.es (6), as.com (7), tuenti.com (8), youtube.com (9), 20minutos.es (13) twitter.com (13), sport.es (17), lavanguardia.es (23) y público.es (25).

\footnotetext{
3 Son datos de la propia compañía (febrero, 2011).

4 El informe se realizó a través de un cuestionario en la red, con 39.709 encuestas validas entre octubre y noviembre de 2010 . Un $84,6 \%$ de los internautas se conectan varias veces al día, más desde casa $(92,5 \%)$ que desde el trabajo (51\%) en horarios de tarde y de noche, en aumento progresivo a partir de de las 17.00 horas: $38,8 \%$ de 17.00 a $19.0,44,2 \%$ de 19.00 a 21.00 y $53,9 \%$ de 21.00 a medianoche.
} 
TABLA 3. Seguidores de las redes sociales. Fuente: AIMC, ORS y Alexa.com

\begin{tabular}{|l|r|r|r|r|}
\hline & Facebook & \multicolumn{1}{c|}{ Tuenti } & \multicolumn{1}{c|}{ Twitter } & Las 3 a la vez \\
\hline \multirow{2}{*}{ ORS } & 11.467 .000 & 7.977 .000 & 1.057 .000 & 14.235 .000 \\
& $78,0 \%$ & $14,0 \%$ & $35,0 \%$ & \\
\cline { 1 - 4 } Alexa.com & $39.8 \%$ & $0.2 \%$ & $9.2 \%$ & \multirow{2}{*}{ AIMC } \\
\cline { 1 - 3 } & $89.9 \%$ & $26,2 \%$ & $21,9 \%$ & \\
\hline
\end{tabular}

La tercera oleada de la encuesta del Observatorio de las Redes Sociales (febrero 2011) señala a Facebook como social con más seguidores (78\% de los entrevistados) pero también como la que tiene menores expectativas de crecimiento porque solo un $6 \%$ de los no usuarios reconoce que tiene intención de darse de alta frente al $29 \%$ que no descarta convertirse en usuario de Twitter y el 18\% de Tuenti. Facebook es también una red que declaran seguir más las mujeres, frente a Twitter y Tuenti, que tienen más presencia entre los hombres.

TABLA 4. Tráfico de usuarios y miembros de las redes sociales. Fuente: conScore.com y ORS (2011)

\begin{tabular}{|l|r|r|r|r|r|r|}
\hline \multirow{2}{*}{} & \multicolumn{3}{|c|}{ Tráfico (conScore) } & \multicolumn{3}{c|}{ Pertenencia (ORS) } \\
\cline { 2 - 7 } & Facebook & Tuenti & Twitter & Facebook & Tuenti & Twitter \\
\hline Facebook & 100,0 & 62,2 & 81,4 & 100,0 & 70,0 & 87,0 \\
\hline Tuenti & 43,2 & 100,0 & 50,0 & 36,0 & 100,0 & 47,0 \\
\hline Twitter & 7,5 & 6,6 & 100,0 & 12,0 & 13,0 & 100,0 \\
\hline
\end{tabular}

Por edades, Facebook mantiene una cuota elevada y equilibrada de usuarios en todos los tramos de edad, Twitter ofrece una baja penetración y está más presente entre usuarios jóvenes y Tuenti tiene un perfil marcadamente juvenil con aceptación descendente a medida que aumenta la edad: del $75 \%$ de los que tiene de 16 a 18 años al $10 \%$ de los mayores de 36 .

TABLA 5. Usuarios de las redes sociales, por edades. Fuente: ORS (2011)

\begin{tabular}{|l|c|c|c|c|}
\hline Edad & Facebook & Twitter & Tuenti & Youtube \\
\hline 16 a 18 años & 80 & 21 & 75 & 73 \\
\hline 19 a 25 años & 81 & 17 & 66 & 55 \\
\hline 26 a 35 años & 79 & 13 & 29 & 38 \\
\hline Más de 36 años & 72 & 13 & 10 & 36 \\
\hline
\end{tabular}

Los datos de AIMC, los del medidor Alexa.com y los del Observatorio de las Redes Sociales coinciden en señalar a Facebook como la red social más numerosa en España, con diferencia sobre las demás. Los medios de comunicación se han posicionado en las redes con mayor número de usuarios y han optado por una segmentación de soportes más que por una integración de actuaciones: Facebook y Twitter, junto a YouTube y, en muy marcadas ocasiones, Tuenti y Flickr. 


\subsection{Los seguidores de los medios en las redes sociales}

En los datos de AIMC resulta especialmente interesante analizar las relaciones de los medios con sus audiencias porque ofrece una segmentación de los niveles de usuarios que siguen páginas de grupos o de marcas: $28 \%$ de los miembros de Facebook, 12 de Tuenti y 17 de Twitter. En los resultados pormenorizados de Facebook y Tuenti no hay referencias explicitas a los medios de comunicación pero sí para Twitter: un $40 \%$ reconoce que sigue a medios, la tercera actividad más popular después de seguir a los famosos $(56 \%)$ y a los amigos $(70 \%)$.

Para aproximarse a los niveles de audiencia de los diarios en las redes sociales se recurrió a comparar las cifras de usuarios de cada medio en una medición realizada el 1 de marzo de 2011 en Facebook y Twitter y el 10 de marzo de 2001 en Tuenti. En un intento de relativizar las cantidades se proyectaron los resultados obtenidos sobre las cifras de audiencia y de tirada de cada medio, según EGM y OJD, respectivamente, para referenciar el peso del número de seguidores aunque siempre teniendo en cuenta que no pueden tomarse como medidores fiables de audiencia del medio (no todos los seguidores leen los contenidos) ni del mensaje (los reenvíos no se computan).

Los datos absolutos de seguidores nos indican que en Facebook los preferidos son los diarios de deportes; en Twitter, las cabeceras generalistas (El País y El Mundo) y en Tuenti hay un desinterés general de todas las cabeceras pero, aun con cifras muy bajas, los que tienen redes propias más amplias con los deportivos. Gratuitos y económicos tiene un seguimiento discreto.

Comparando con las cifras del EGM, el mayor nivel de seguimiento en redes en relación a su audiencia en papel es Público. Globalmente, hay un grupo de 3 diarios generalistas (El País, El Mundo y Público, por orden) y 2 deportivos (El Mundo Deportivo y Marca) que se sitúan por encima de la barrera de los 100.000 seguidores. El aventajado en Twitter es El País. Sus seguidores duplican a sus más próximos competidores por el liderato de audiencia, El Mundo y El Mundo Deportivo. Hablamos de seguidores directos sin posibilidad de medida del reenvío que los internautas hagan de las aportaciones del medio en la red social.

TABLA 6. Audiencias de diarios en las redes sociales. Fuente: Elaboración propia

\begin{tabular}{|c|c|c|c|c|c|c|c|c|c|c|c|}
\hline \multirow{2}{*}{ MEDIO } & \multirow{2}{*}{ EGM } & \multirow{2}{*}{ OJD } & \multicolumn{3}{|c|}{ Facebook } & \multicolumn{3}{|c|}{ Twitter } & \multicolumn{3}{|c|}{ Tuenti } \\
\hline & & & Usuarios & $\begin{array}{c}\% \\
\text { audiencia }\end{array}$ & $\begin{array}{l}\% \\
\text { tirada }\end{array}$ & Usuarios & $\begin{array}{c}\% \\
\text { audiencia }\end{array}$ & $\begin{array}{l}\% \\
\text { tirada }\end{array}$ & Usuarios & $\begin{array}{c}\% \\
\text { audiencia }\end{array}$ & $\begin{array}{l}\% \\
\text { tirada }\end{array}$ \\
\hline \multicolumn{12}{|c|}{ Prensa generalista } \\
\hline El Pais & 1.924 .000 & 383.426 & 65.639 & 3,41 & 17,12 & 418.381 & 21,71 & 109,12 & 1.616 & 0,08 & 0,42 \\
\hline El Mundo & 1.282 .000 & 292.608 & 25.894 & 2,02 & 8,85 & 226.248 & 17,64 & 77,32 & 470 & 0,04 & 0,16 \\
\hline El Periódico & 778.000 & 138.454 & 12.837 & 1,64 & 9,27 & 2.134 & 0,27 & 1,54 &.- & & \\
\hline $\begin{array}{l}\text { Vanguardia } \\
\text { (catalán) }\end{array}$ & 757.000 & 197.503 & $\begin{array}{r}3.257 \\
552\end{array}$ & $\begin{array}{l}0,43 \\
0,07\end{array}$ & $\begin{array}{l}1,64 \\
0,28\end{array}$ & 7.349 & 0,97 & 3,72 & -. & & \\
\hline$A b c$ & 756.000 & 251.337 & 32.995 & 4,36 & 13,12 & 26.397 & 3,49 & 10,50 & 543 & 0.07 & 1,65 \\
\hline $\begin{array}{l}\text { La Voz de } \\
\text { Galicia }\end{array}$ & 585.000 & 98.829 & 14.449 & 2,47 & 14,62 & 4.861 & 0,83 & 4,92 & 425 & 0,07 & 0,43 \\
\hline El Correo & 475.000 & 106.684 & 1.061 & 0,43 & 1,93 & 1.917 & 0,40 & 1,80 & & & \\
\hline La Razón & 357.000 & 118.862 & 1.332 & 0,37 & 1,12 & 1.915 & 0,53 & 1,61 & & & \\
\hline
\end{tabular}




\begin{tabular}{|c|c|c|c|c|c|c|c|c|c|c|c|}
\hline $\begin{array}{l}\text { La Nueva } \\
\text { España }\end{array}$ & 350.000 & 57.396 & 6.475 & 1,85 & 11,28 & 2.942 & 0,84 & 5,21 & 162 & 0,05 & 0,33 \\
\hline $\begin{array}{l}\text { Heraldo de } \\
\text { Aragón }\end{array}$ & 282.000 & 48.615 & 3.029 & 1,07 & 6,23 & 2.352 & 0,83 & 4,78 & $* * *$ & & \\
\hline Levante & 268.000 & 34.973 & 3.065 & 1,14 & 8,76 & 2.655 & 0,99 & 7,59 & & & \\
\hline Faro de Vigo & 268.000 & 38.664 & 2.091 & 0,78 & 5,41 & 288 & 0,11 & 0,74 & & & \\
\hline Diario Vasco & 265.000 & 74.146 & $\cdots *$ & - & - & 2,401 & 0,91 & 3,23 & & & \\
\hline Público & 247.000 & 83.497 & 55.000 & 22,26 & 65,87 & 101.405 & 41,05 & 121,45 & & & \\
\hline \multicolumn{12}{|c|}{ Prensa deportes } \\
\hline Marca & 2.888 .000 & 278.947 & 124.568 & 4,31 & 44,66 & 133.514 & 4,62 & 47,86 & 37.155 & & \\
\hline As & 1.395 .000 & 211.342 & 155.365 & 11,12 & 73,51 & 76.740 & 5,49 & 6,31 & 25.938 & & \\
\hline Sport & 737.000 & 102.853 & 146.143 & 19,81 & 142,09 & 33.205 & 4,50 & 32,28 & & & \\
\hline $\begin{array}{l}\text { El Mundo } \\
\text { Deportivo }\end{array}$ & 658.000 & 101.669 & 74.926 & 11,38 & 73,70 & 207.660 & 31,54 & 204,25 & & & \\
\hline \multicolumn{12}{|c|}{ Prensa económica } \\
\hline La Gaceta ${ }^{* \hbar}$ & 185.000 & 43.771 & 453 & 0,24 & 1,03 & 3,397 & 1,84 & 7,76 & & & \\
\hline Expansión & 182.000 & 41.550 & 3.606 & 1,98 & 8,68 & 11.404 & 6,27 & 27,45 & & & \\
\hline \multicolumn{12}{|c|}{ Prensa gratuita } \\
\hline 20 minutos" & 2.279 .000 & 702.518 & 16.155 & 0,71 & 2,30 & 3.131 & 0,14 & 0,46 & 1.276 & & \\
\hline$Q u e^{*}$ & 1.496 .000 & 619.129 & 13.977 & 0,93 & 2,58 & 1.173 & 0,08 & 0,19 & 739 & & \\
\hline $\operatorname{Adn} n^{*}$ & 1.203 .000 & 575.887 & 2.328 & 0,19 & 0,40 & 8.883 & 0,74 & 1,54 & & & \\
\hline
\end{tabular}

Twitter es la red social en la que los medios parecen haber encontrado mejor acomodo porque permite el envío de titulares (similar al sistema RSS de alertas informativas) sin necesidad de un nuevo proceso de elaboración del mensaje, aunque las principales cabeceras personalizan su envío buscando proximidad y empatía con un lenguaje coloquial y segunda persona en el trato al usuario. La propia red se orienta hacia contenidos de actualidad al estimular la participación de este modo: "Dile al mundo lo que está pasando en 140 caracteres o menos". Y los medios han respondido ajustando su presencia al formato del diario y a las preferencias de los seguidores con enlaces a secciones temáticas de la edición ${ }^{5}$.

Los diarios deportivos han sabido ver en Facebook el escenario ideal para alimentar los debates pasionales e intelectuales sobre los equipos de referencia en el fútbol. Facebook es la red con mayor penetración entre los internautas pero con cifras de seguimientos similares o algo inferiores a las de Twitter. Publicar en el muro requiere una gestión de la comunicación como producto que no todas las cabeceras atienden pero que las audiencias recompensan. Además de los deportivos, El País y Público tienen cifras de seguidores elevadas en comparación con el resto de periódicos. Les siguen $A b c$ y los gratuitos. Los económicos están entre los diarios menos seguidos en esta red social.

${ }^{5}$ Desde Twitter se definen como "red de información" y no como "red social". Intervención de Laura I. Gómez, responsable de internacionalización de Twitter, en el I Congreso Iberoamericano de Redes Sociales (Burgos, febrero de 2011). 
Tuenti es la red social menos usada por los diarios como distribuidor de contenidos. Seguramente por su segmentación de público juvenil. Aunque desde un punto de vista comercial es el espacio perfecto para conectar con un target que debería ser preferencial en las estrategias de expansión como nuevos usuarios de la marca. Los contenidos que aportan los diarios son casi siempre secundarios y aunque, por ejemplo, sería posible sincronizar los envíos en Twitter y Tuenti, las cifras de seguidores son muy bajas, en algunos casos casi insignificantes.

Las cifras de escaso eco en Tuenti afectan también a los diarios gratuitos. En la edición impresa cuentan con una red de distribución que prima los campus universitarios $^{6}$ para llegar a los jóvenes a través de la gratuidad con un producto que permanentemente remite hacia el entorno virtual; sin embargo en las redes sociales (incluso la de perfil más joven como en Tuenti) la gratuidad deja de ser un elemento diferenciador y las audiencias se decantan hacia las cabeceras de referencia.

Se tiende a una sincronización de Facebook y Twitter. Facebook está consolidada, con menos posibilidades de crecer pero abultadamente distanciada en el número de seguidores respecto a Twitter, que ofrece en cambio la facilidad de uso como microblog: remite los titulares de las noticias de la edición del día en la versión on line y redirige al usuario a la web del diario porque los 140 caracteres que admiten los Tweet dan para poco más.

TABLA 7. Comparativa de Facebook y Twitter. Fuente: Elaboración propia

\begin{tabular}{|l|l|}
\hline \multicolumn{1}{|c|}{ Facebook } & \multicolumn{1}{c|}{ Twitter } \\
\hline Acceso libre, previo registro & Acceso libre, previo registro \\
\hline Universal & Universal \\
\hline $\begin{array}{l}\text { Alta penetración en todos los grupos de } \\
\text { edades }\end{array}$ & $\begin{array}{l}\text { Media/baja penetración en todos los grupos } \\
\text { de edad, un poco más alta en los jóvenes }\end{array}$ \\
\hline $\begin{array}{l}\text { Comunicación Interpersonal privada y } \\
\text { colectiva }\end{array}$ & Comunicación colectiva. Inmediatez \\
\hline $\begin{array}{l}\text { Relación con conocidos. Los miembros de } \\
\text { nuestra red necesitan ser aceptados. }\end{array}$ & $\begin{array}{l}\text { Relación con conocidos y desconocidos. No } \\
\text { conocemos a quien nos sigue }\end{array}$ \\
\hline $\begin{array}{l}\text { Contenidos más próximos a la esfera } \\
\text { intima de la comunicación informal }\end{array}$ & $\begin{array}{l}\text { Contenidos próximos a la esfera pública de } \\
\text { la comunicación informal y de la oficial }\end{array}$ \\
\hline Multimedia & Textual o hipertextual \\
\hline $\begin{array}{l}\text { Impresiones y hechos. Credibilidad en las } \\
\text { personas }\end{array}$ & $\begin{array}{l}\text { Hechos y experiencias. Credibilidad está en } \\
\text { el mensaje y en los medios }\end{array}$ \\
\hline $\begin{array}{l}\text { Uso para contacto con amigos. Se basa } \\
\text { mas en relaciones afectivas }\end{array}$ & $\begin{array}{l}\text { Uso para contacto con actualidad, } \\
\text { profesional y amistad. Se basa más en } \\
\text { relaciones intelectuales }\end{array}$ \\
\hline $\begin{array}{l}\text { Difusor de contenidos. Recuperación } \\
\text { cronológica o por usuario }\end{array}$ & $\begin{array}{l}\text { Difusor de enlaces. Recuperación con } \\
\text { motores de búsqueda }\end{array}$ \\
\hline $\begin{array}{l}\text { Para feedback (diálogo). Queremos hablar } \\
\text { sincrónica o diacrónicamente }\end{array}$ & $\begin{array}{l}\text { Para reenvío (discurso). Queremos que nos } \\
\text { lean... pero solo podemos decidir a quien } \\
\text { leemos }\end{array}$ \\
\hline
\end{tabular}

${ }^{6}$ TÚNNEZ, Miguel, “Jóvenes y prensa en papel”, en Estudios del Mensaje Periodístico, 2009, n. 15. 


\begin{tabular}{|l|l|}
\hline Relaciones bidireccionales para compartir. & $\begin{array}{l}\text { Relaciones unidireccionales para ver/contar. } \\
\text { Creamos una red interactiva con diferentes } \\
\text { Vemos lo que publican los miembros que } \\
\text { hemos decidido seguir y ha decidido seguir } \\
\text { niveles de privacidad. Podemos mostrar a } \\
\text { todos y ver lo que muestran. }\end{array}$ \\
él. Solo me ven los que me siguen.
\end{tabular}

\subsection{Los contenidos}

Los medios usan las redes como nuevas audiencias para sus contenidos. No hay un modelo único que defina la presencia de los diarios en las redes sociales. Cada uno ha marcado una estrategia diferente en los modos de relacionarse con los internautas, la forma de presentar sus contenidos, los niveles de participación que permiten, la bidireccionalidad o interactividad en el muro. Para profundizar en el seguimiento de la presencia de medios en las redes sociales se hizo un seguimiento de los contenidos que aportaban los diarios que superaban en Facebook los 10.000 seguidores A lo largo de una semana se revisaron y contabilizaron los post publicados. Se vigiló si se trata de enlaces o se presentaban con textos elaborados, si estimulaban la participación de los lectores, el tipo de lenguaje utilizado y la cantidad de respuestas conseguidas como comentarios y como 'me gusta' activados por los seguidores.

Los resultados no son homogéneos. Hay desde cabeceras con muros cerrados a otras que permiten a la audiencia aportar contenidos propios; las que anuncian la reunión para decidir contenidos y dicen que admiten propuestas a las que limitan su presencia a sincronizar Twitter y Facebook para dosificar la entrega de contenidos; de las que cierran las redes en los fines de semana o a media tarde a las que funcionan prácticamente las 24 horas renovando contenidos; desde las que ofrecen 3 o 4 propuestas por día hasta las que casi saturan con más de 37 actualizaciones en una jornada.

TABLA 8. Contenidos de los medios en las redes sociales. Fuente: Elaboración propia

\begin{tabular}{|c|c|c|c|c|c|c|c|}
\hline \multirow[b]{2}{*}{ MEDIO } & \multirow[b]{2}{*}{ Usuarios } & \multicolumn{5}{|c|}{ Post } & \multirow[b]{2}{*}{ Días } \\
\hline & & Día & $\begin{array}{l}\text { Texto } \\
\text { propio }\end{array}$ & $\begin{array}{c}\text { Invita a } \\
\text { participar }\end{array}$ & $\begin{array}{c}\text { Suben } \\
\text { usuarios }\end{array}$ & $\begin{array}{l}\text { Responde } \\
\text { medio }\end{array}$ & \\
\hline As & 155.365 & 11,9 & si & A veces & sí & no & 7 \\
\hline Sport & 146.143 & 37,0 & sí & A veces & sí & sí & 7 \\
\hline Marca & 124.568 & 3,1 & sí & Frecuentemente & no & sí & 7 \\
\hline El Mundo Deportivo & 74.926 & 6,7 & si & Frecuentemente & no & no & 7 \\
\hline El Pais & 65.639 & 7,9 & sí & sí & no & no & 7 \\
\hline Público & 55.000 & 22,6 & sí & si & no & no & 7 \\
\hline$A b c$ & 32.995 & 9,8 & si & Frecuentemente & no & no & 5 \\
\hline El Mundo & 25.894 & 6,4 & si & Frecuentemente & no & no & 5 \\
\hline 20 mimutos* & 16.155 & 10,6 & no & no & no & no & 7 \\
\hline La Voz de Galicia & 14.449 & 15,2 & Apenas & no & no & no & 6 \\
\hline$Q u e^{*}$ & 13.977 & 3,8 & $\mathrm{si}$ & Frecuentemente & no & si & 5 \\
\hline El Periódico & 12.837 & 4,9 & sí & A veces & no & no & 7 \\
\hline
\end{tabular}

No se encontraron contenidos propios para la red social más allá del texto que presenta al enlace, que no aparece en todos los casos. No ha de ser la motivación principal porque el objetivo no es promover un nuevo producto informativo sino potenciar la difusión y aumentar la audiencia del que ya existe. Pero tampoco se ven esfuerzos por lograr que los contenidos se difundan en técnica viral. Se usan las redes como primer difusor viral del diario on line pero no se estimula que el proceso se replique entre los usuarios de las redes que siguen al periódico. 
Los principales medios personalizan sus entradas en las redes, tanto en Facebook como en Twitter, e incluyen expresiones que promuevan el reenvío del enlace o el comentario del destinatario, básicamente con preguntas directas (El Pais: “iSe te ocurre alguna película basada en un libro que no hayan añadido en su listado?"; El Mundo “¿Has tenido problemas por la meteorología?”) o con preguntas e interacciones que invitan a ser proactivo en la red social (Abc: “¿Has ido al trabajo en coche? ¿Cuál ha sido tu percepción sobre el cumplimiento de la nueva norma? ¡Cuéntanos!”; Público: "Ahora tenemos información de todas las localidades y previsiones a 7 días. ¿Qué os parece?”)

\section{4. ¿Bidireccionales o interactivos?}

La comunicación 2.0 ha traspasado las fronteras de la web debido a que la evolución de las herramientas tecnológicas ha permitido que la vida cotidiana se piense en términos de redes sociales como escenario de interactividad grupal e individual, como forma de organización pública y privada, como manifestación unipersonal y colectiva. Lo que comenzó siendo una forma de manifestación virtual de la esfera interpersonal privada (relaciones entre amigos) generó una nueva fórmula de relación social en la que hoy participan 940 millones de personas en el mundo ${ }^{7}$. Las redes sociales y la filosofía 2.0 se han integrado en todo tipo de organizaciones -con o sin ánimo de lucro, públicas o privadas- de manera que web 2.0 es también empresa 2.0, política $2.0 \mathrm{o}$ Gobierno 2.0. Y las redes son espacio de encuentro, de negocio y de debate.

La participación en los entornos 2.0 debería fundamentase en el Compromiso 2.0 (TÚÑEZ y SIXTO, 2011): no basta con la presencia, sino que se exige también la contribución activa tanto de los creadores como de los usuarios, intercambiando opiniones y contenido, de manera que ambos obtengan beneficios.

Todos los diarios analizados, excepto Marca, Qué y Sport, que en ocasiones dialogan, acostumbran a trabajan con un flujo de comunicación que podríamos etiquetar como 'aparentemente' interactiva con sus seguidores porque ofrecen contenidos y alimentan las respuestas pero no responden a las aportaciones de los usuarios en su muro. Es un modelo bidireccional pero sin retorno, con lo que no podemos afirmar que se mantenga un diálogo en las redes sociales entre el medio y sus seguidores, pero sí entre sus seguidores que aprovechan las publicaciones en el muro o los espacios de foros para debatir entre ellos.

Los cuatro diarios de deportes, El País, Público y El Mundo también son los que tienen muros más interactivos, aunque se trate casi siempre de una comunicación bidireccional sin respuesta del medio y la interacción real se da en el debate entre los usuarios.

TABLA 9. Interactividad de los usuarios de los medios en las redes sociales. Fuente: Elaboración propia.

\begin{tabular}{|l|c|r|r|r|r|r|r|}
\hline \multirow{2}{*}{ MEDIO } & \multirow{3}{*}{ Usuarios } & \multicolumn{3}{|c|}{ Comentarios } & \multicolumn{3}{|c|}{ Me gusta } \\
\cline { 3 - 8 } & & $\begin{array}{c}\text { Por } \\
\text { dia }\end{array}$ & $\begin{array}{c}\text { Por } \\
\text { post }\end{array}$ & $\begin{array}{c}\text { \% } \\
\text { usuarios }\end{array}$ & Por dia & $\begin{array}{c}\text { Por } \\
\text { post }\end{array}$ & $\begin{array}{c}\% \\
\text { usuarios }\end{array}$ \\
\hline As & 155.365 & 387,9 & 32,7 & 0,25 & $1.034,1$ & 87,2 & 0,66 \\
\hline Sport & 146.143 & 221,0 & 6,0 & 0,15 & 582,0 & 15,7 & 0,40 \\
\hline Marca & 124.568 & 133,6 & 42,5 & 0,11 & 256,6 & 81,6 & 0,21 \\
\hline
\end{tabular}

7 Datos del estudio de InSites Consulting (disponible en http://blog.insites.be/), referentes a 2010. 


\begin{tabular}{|l|r|r|r|r|r|r|r|}
\hline El Mundo Deportivo & 74.926 & 143,0 & 21,3 & 0,19 & 358,7 & 53,0 & 0,48 \\
\hline El País & 65.639 & 309,3 & 39,4 & 0,47 & 438,3 & 55,8 & 0,67 \\
\hline Público & 55.000 & 573,7 & 25,4 & 1,04 & $1.078,7$ & 47,8 & 1,96 \\
\hline Abc & 32.995 & 154,0 & 15,7 & 0,47 & 209,0 & 21,3 & 0,63 \\
\hline El Mundo & 25.894 & 138,8 & 21,7 & 0,53 & 140,4 & 21,9 & 0,54 \\
\hline 20 mimutos * & 16.155 & 69,7 & 6,6 & 0,43 & 129,6 & 12,3 & 0,80 \\
\hline La Voz de Galicia & 14.449 & 89,5 & 5,9 & 0,62 & 162,5 & 10,7 & 1,12 \\
\hline Qué * & 13.977 & 30,4 & 8,0 & 0,22 & 43,8 & 11,5 & 0,31 \\
\hline El Periódico & 12.837 & 22,3 & 4,6 & 0,17 & 45,9 & 9,4 & 0,36 \\
\hline \multicolumn{7}{|c|}{ Media } & \multicolumn{7}{|c|}{0,39} & & & 0,68 \\
\hline
\end{tabular}

Para ver el peso de la interacción se contabilizaron los comentarios y los 'me gusta' que durante una semana aparecieron en los temas que publicaron en sus páginas de $\mathrm{Fa}$ cebook los diarios que cuentan con más de 10.000 seguidores en esa red social. El resultado es muy similar en los 12 periódicos analizados independientemente del volumen de seguidores, que oscila entre los apenas 13.000 de El Periódico y los más de 150.000 de As. Solo uno de cada 150 seguidores de un medio en Facebook se anima a expresar que le gusta un tema $(0,68 \%)$ y uno de cada 250 deja un comentario $(0,39 \%)$. A pesar de que (como se observa en la Tabla 9) los porcentajes son muy bajos, es posible que estén distorsionados al alta porque hay usuarios que dejan varios comentarios en un mismo día.

Se dan, sin embargo, interesantes formas de participación de la audiencia en los contenidos, en línea con la web2.0. Por ejemplo, se incorporan a la producción informativa sus opiniones, sus alertas de situaciones o sus testimonios como protagonistas o testigos de acontecimientos ${ }^{8}$. Tres ejemplos: Qué buscando testimonios para una noticia ("Hola, en el periódico van a hacer una noticia sobre ahorro energético y queremos contar con vuestra opinión. Bombillas, 110 por hora, cambio de ruedas... ¿Qué propones tú para ahorrar energía? Esperemos vuestras respuestas, muchas gracias"), 20 minutos invitando a asistir al consejo de redacción del diario ("Comenta, propón, critica... Estás invitado a diario a la reunión de redacción de 20minutos.es") o $\mathrm{La} \mathrm{Voz}$ de Galicia aportando testimonio gráfico de un lector ("El tornado de Arousa, en acción, El lector Jose Antonio Leiro Búa nos envía este vídeo").

También se han encontrado, aunque son poco frecuentes, forma de participación lúdicas a través de concursos o sorteos, como este ejemplo de Sport: "Estamos de nuevo de enhorabuena. La página de SPORT en Facebook ha superado la barrera de los 100.000 fans $[\ldots]$ Por eso queremos sortear entre nuestro seguidores tres réplicas con radiocontrol del Ferrari", o este de El Correo: "Estrenamos página en Facebook. Entre los nuevos fans hasta el próximo lunes 8 de febrero sortearemos 5 forros polares del Athletic”. Los pocos concursos/sorteos que se incluyen como norma de fidelización redirigen a la web del diario o a microwebs específicas y acostumbran a ser iniciativas de publicidad compartida por el medio y una marca comercial.

${ }^{8}$ Nada mas conocerse el terremoto de Japón (marzo de 2011), los principales medios apostaron por las redes sociales como herramienta para conseguir testimonios de primera mano de afectados por el seísmo. 


\subsection{Estrategias comerciales}

Se ha comenzado a ver un nuevo escenario informativo que parece limitarse más a una forma de lograr visibilidad del medio (aumentar la presencia de la marca) que a la potenciación de un nuevo canal de distribución que es, a su vez, un escenario de negocio pujante por la cantidad de de usuarios que se mueven en él cada día.

Apenas se han encontrado propuestas que acompañen la oferta gratuita de los contenidos con iniciativas que promuevan la comercialización de productos propios. Las estrategias son escasas aunque pueden enumerarse una variedad de ejemplos que podrían inducir a pensar lo contrario. Las acciones identificadas se detallan en la Tabla 10.

TABLA 10. Algunas estrategias promocionales de los medios en las redes sociales. Fuente: Elaboración propia

\begin{tabular}{|c|c|}
\hline Acción & Ejemplos \\
\hline $\begin{array}{l}\text { Remitir a otros productos de otros } \\
\text { medios del grupo }\end{array}$ & $\begin{array}{l}\text { Marca: "Mou y Pep nos muestran las ventajas de leer MARCA en } \\
\text { Orbyt. ¿Aguantarán como amigos hasta el final?" } \\
\text { El Pais: "Lee, pregunta e infórmate en Eskup". }\end{array}$ \\
\hline $\begin{array}{l}\text { Fomentar el tráfico hacia la web o } \\
\text { microwebs asociadas }\end{array}$ & $\begin{array}{l}\text { El Pais: "Esta tarde toca debate sobre periodismo de futuro (...) Síguelo a } \\
\text { partir de las } 18.30 \text { en nuestra web" } \\
\text { As: ¿Crees que sabes más que nadie de fútbol? Demuéstralo jugando a la Liga } \\
\text { Fantasy de la LFP en www.estoesotraliga.es }\end{array}$ \\
\hline $\begin{array}{l}\text { Direccionar seguidores entre redes } \\
\text { sociales }\end{array}$ & $\begin{array}{l}\text { El Mundo: 3-F: "Un grupo de guardias civiles ha irrumpido en el Congreso y } \\
\text { se lo contaremos en directo. Participe a través de Twitter con el hashtag } \\
\text { \#Recreacion23F" } \\
\text { Mundo Deportivo: "Atención. A partir de ya mismo conectamos... en directo! } \\
\text { con la sala de prensa para retransmitir por streaming la comparecencia de } \\
\text { Xavi" } \\
\text { Sport: ENCUESTA // ¿Qué tweet te ha gustado más? http://bit.ly/iiuHPq }\end{array}$ \\
\hline $\begin{array}{l}\text { Promocionar productos asociados a } \\
\text { la edición en papel }\end{array}$ & $\begin{array}{l}\text { Diario Público: "Mañana con tu Público recibirás un libro de la Colección } \\
\text { Voces Críticas" } \\
\text { As: "Este domingo, la cartilla con tu ejemplar de Diario AS Consigue la manta } \\
\text { del Real Madrid gratis con AS" }\end{array}$ \\
\hline $\begin{array}{l}\text { Potenciar versiones on line del } \\
\text { diario }\end{array}$ & El Periódico: Consulta ya el e-Periódico de hoy \\
\hline $\begin{array}{l}\text { Promover otros medios o productos } \\
\text { o actividades del grupo de } \\
\text { comunicación al que pertenece el } \\
\text { medio }\end{array}$ & $\begin{array}{l}\text { La Vanguardia: hagoclic.vom y faigclic.com (Canal de noticia sen la red, } \\
\text { promovido por el Grupo Godó) } \\
\text { Abc: } \leqq \text { II Festival Iberoamericano de Cortos ABC } \\
\text { El Mundo: Máster Oficial en Periodismo de Unidad Editorial y la Universidad } \\
\text { San Pablo-CEU }\end{array}$ \\
\hline $\begin{array}{l}\text { Potenciar la venta de productos del } \\
\text { medio }\end{array}$ & Diario Público: Máquinas útiles, máquinas curiosas en la tienda de Público. \\
\hline
\end{tabular}

Se detectó muy poca presencia de actividades comerciales externas que hagan de la red social y de las relaciones creadas en ella un canal de promoción y venta de publicidad o directamente de productos asociados, como ocurre, por ejemplo, en $E l$ Mundo con www.detiendasporelmundo.es o en la propuesta diaria de Público (“...iPásate por nuestro espacio de cupones!"), de Sport ("i... entra en la tienda de SPORT en Shirtcity!”) o de Marca (“.. ha llegado el momento de presentaros a un gran compañero que acaba de llegar a Facebook iiYa tenéis por estas tierras a Marca Sports Cafe!! ..."). 
Los darios trabajan en actualizaciones simultáneas para varias redes (Facebook desde Twitter, por ejemplo) o apuestan por fomentar Twitter desde Facebook ${ }^{9}$ pero no se ha encontrado ningún caso de multipresencia sincronizada en muchas redes sociales que permita pensar en una estrategia planificada de gestión proactiva de la cabecera del diario como marca que aspira a posicionarse en nuevos espacios o entornos de comunicación social.

Tampoco se encontró ninguna iniciativa que redunde en promover la fidelización en la red (ventajas por ser del grupo) para el diario impreso, ni, por ejemplo, que estimulen a los seguidores a aportar nuevos lectores.

\section{Conclusiones}

Las redes sociales han evolucionado como herramienta de comunicación interpersonal y de la esfera íntima a herramientas de comunicación personal y social en las esferas íntima y pública. El incremento de propuestas de actividades en una misma red y de la multiplicación de puntos y formas de acceso está creando un sistema de híper comunicación que va modificando los hábitos iniciales de la redes (comunicación interpersonal) y que mueve los afectos como motor de pertenencia (encuentro con amigos) hacia el intelecto (redes temáticas o contacto con la actualidad informativa).

Los medios usan las redes como nuevas audiencias para sus contenidos en la versión on line. No hay un modelo único que defina la presencia de diarios en las redes sociales sino que cada uno ha marcado una estrategia diferente en los modos de relacionarse con los internautas. La comunicación en Twitter se sitúa más próxima a la esfera pública de la comunicación informal y de la comunicación oficial. En Facebook y Tuenti son contenidos más próximos a la esfera íntima de la comunicación informal. Los medios se sitúan en la esfera pública y la comunicación oficial, por lo que blogs, foros, canales abiertos como YouTube y redes sociales como Twitter parece aproximarse más a su necesidad de difundir contenidos.

- Comparativamente con sus audiencias en soporte impreso, los periódicos obtienen mejores resultados de seguidores en Twitter. Aunque Facebook es la red con más seguidores en España y multiplica por 3 los seguidores de Twitter los medios apuestan por redireccionar audiencias de Facebook a Twitter, la red que permite envío de mensajes con menor nivel de elaboración. Twitter se perfila como la red social por la que apuestan los medios.

- Independientemente del número de seguidores (la muestra va de 13.000 a 150.000), solo uno de cada 250 es pro activo (deja un comentario el 0,39\%). Se observó que en todos los medios se repite la presencia de usuarios hiperactivos que colocan anotaciones en varios temas. El resultado es muy similar en todos los periódicos analizados

- Para los jóvenes internet es un escenario de comunicación interpersonal, de documentación, de ocio y divertimento con descargas de juegos y vídeos, de actividades de formación y, después, de consulta de diarios para consumo de información de ac-

9 "Manual para principiantes de Twitter", en Facebook de La Voz de Galicia. 
tualidad. La edad de inicio en el uso de la red se va reduciendo pero los diarios desatienden su presencia en la red social más juvenil: Tuenti. No tienen presencia ni la enlazan desde su muro y los que están presentes no aportan contenidos de actualidad en niveles similares a los que difunden en Facebook y Twitter.

- Las estrategias de los medios tradicionales se orientan más a innovar en aplicaciones y herramientas en sus entornos virtuales que hacia variaciones en los contenidos a través de la priorización de nuevos temas o la creación de nuevos productos, tanto en la red como en el papel. Se potencia la presencia en redes sociales pero excepto algunos casos de Twitter y algunas excepciones en Facebook, la bidireccionalidad con la audiencia no encuentra respuesta desde los periódicos.

- Tampoco se encuentran contenidos específicos para la red social más allá del texto que presenta al enlace, que no aparece en todos los casos. Se usan las redes como primer difusor en técnica viral pero no se estimula que el proceso se replique entre los usuarios de las redes que siguen al diario. Como mucho, desde los textos se estimula la participación de la audiencia.

- Todos los diarios analizados, excepto Marca, Qué y Sport, y que en ocasiones dialogan, no responden a las aportaciones de los usuarios en su muro. Es un modelo bidireccional sin retorno, con lo que no podemos afirmar que se produzca diálogo en las redes sociales entre el medio y sus seguidores. Se dan, sin embargo, interesantes formas de participación de la audiencia en los contenidos, en línea con la web2.0, cuando se incorporan a la producción informativa sus opiniones, sus alertas de situaciones o sus testimonios como protagonistas o testigos de acontecimientos. También se han encontrado, aunque son poco frecuentes, formas de participación lúdica a través de concursos o sorteos.

- Las redes sociales son un espacio de intercomunicación personal basada en la interactividad multidireccional entre sus miembros. Han creado y desarrollado sus códigos y sus pautas de uso. Las empresas (los medios entre ellos) y algunas organizaciones han visto en los tráficos millonarios de usuario un nuevo escenario para la difusión de ideas productos y servicios. El uso de los espacios creados en las redes sociales como plataforma de marca y escenario de negocio es el aspecto en el que se ha detectado una menor actividad de los medios analizados.

\section{Referencias Bibliográficas}

ASOCIACIÓN PARA LA INVESTIGACIÓN DE MEDIOS DE COMUNICACIÓN (AIMC) "Navegantes en la red", febrero 2011,. Madrid DL M-8018-2011, en http://www.aimc.es/-Navegantes-en-la-Red-.html [Última fecha de consulta: 1 de marzo de 2011]

ESTUDIO GENERAL DE MEDIOS (EGM), en http://www.aimc.es//-Datos-EGMResumen-General-.html [Última fecha de consulta: 20 de febrero de 2011]

CAMPOS FREIRE, Francisco (2008): "Las redes sociales trastocan los modelos de los medios de comunicación tradicionales", en Revista Latina de Comunicación Social, 63, páginas 287 a 293: http://www.revistalatinacs.org/_2008/23_34_Santiago/Francisco_Campos.html [Última fecha de consulta: 15 de enero de 2011 ] 
OFICINA DE LA JUSTIFICACIÓN DE LA DIFUSIÓN (OJD) (http://www.ojd.es/) Buscador de publicaciones, disponible en: http://www.ojd.es/Introl/Portal/buscador_de_publicaciones_primer_filtro/_784cv_dXYIPhXeCo9mRrKQ\# [Última fecha de consulta: 12 de marzo de 2011]

INSTITUTO NACIONAL DE ESTADÍSTICA (INE)Encuesta sobre equipamiento y uso de tecnologías de la información y comunicación en los hogares 2010. Disponible en: http://www.ine.es/jaxi/menu.do?type=pcaxis\&path=/t25/p450\&file =inebase [Última fecha de consulta: 15 de febrero de 2011]

OBSERVATORIO DE LA REDES SOCIALES, Tercera Oleada (2011) Disponible en http://www.tcanalysis.com/2011/02/22/publicamos-la-3\%C2\%AA-ola-delobservatorio-de-redes-sociales/ [Última fecha de consulta: 28 de febrero de 2011]

RUSHKOFF, Douglas (1996): Media Virus. Hidden agendas in popular culture. New York, Ballantine Books.

SANTESMASES MESTRE, Miguel (2007): Marketing. Conceptos y estrategias, $5^{\text {a }}$ edición revisada. Madrid, Pirámide.

SIVERA BELLO, Silvia (2008): Marketing viral. Barcelona, Editorial UOC.

TÚÑEZ, Miguel y SIXTO, José (2011): "Redes sociales, política y Compromiso 2.0: La comunicación de los diputados españoles en Facebook". Revista Latina de Comunicación Social, 66, pp. 210 a 246: http://www.revistalatinacs.org/11/art/ 930_Santiago/09_Tunez.html [Última fecha de consulta: 11 de marzo de 2011]

TUÑEZ, Miguel; SOLANA, María Yolanda; y ABEJÓN, Paloma (2010): "Nuevos entornos, nuevas demandas, nuevos periodistas". Estudios del Mensaje Periodistico, Vol. 16, pp. 79-94. Madrid, Servicio de Publicaciones de la Universidad Complutense. 